\title{
The synthesis, oxidation and characterization of GLP-1 peptide receptor fragments
}

\author{
János Szolomájer ${ }^{1}$, Zoltán Kele ${ }^{1}$, Gábor K. Tóth ${ }^{1}$, Pál Stráner $^{2}$, András Perczel ${ }^{2}$ \\ ${ }^{1}$ University of Szeged, Departmentof Medical Chemistry, Hungary \\ ${ }^{2}$ Eötvös Loránd University, MTA-ELTE Protein Model. Res. Group and Laboratory of Structural Chemistry and Biology, Hungary
}

https://doi.org/10.17952/35EPS.2018.253

Glucagon is a 29-amino acid peptide hormone that is produced by the post-translational cleavage of proglucagon, which is a 160 -amino acid precursor polypeptide expressed in pancreatic $\alpha$-cells, intestinal L cells and brain cells. In the intestine and the brain, proglucagon cleavage is catalysed by the PC1/3 enzyme, leading to the formation of glucagon-like peptide-1 (GLP-1), glucagon-like peptide-2 (GLP-2), glicentin and oxintomodulin. GLP-1 is a 31 -amino acid peptide hormone that has approximately $50 \%$ amino acid sequence homology with glucagon, which is secreted mainly by the intestinal L-cells in response to nutrient ingestion. Despite this high degree of sequence homology, glucagon and GLP-1 perform opposing actions in glucose homeostasis. [1] The main physiological role of glucagon is to protect the organism against the damaging effects of hypoglycaemia, especially in the central nervous system, which requires a continuous supply of glucose. The central action of glucagon is to increase the circulating levels of glucose by stimulating glycogenolysis and gluconeogenesis and, at the same time, to inhibit glycolysis and glycogenesis in the liver. These changes in glucose metabolism, which are induced by glucagon, in turn induce an increase in hepatic glucose output, to ensure an appropriate supply of glucose to the body and the brain. GLP-1 stimulates glucosedependent insulin release from pancreatic $\beta$-cells, inhibits glucagon secretion and increases $\beta$-cell proliferation, which contributes to improving the control of the blood glucose levels. Furthermore, GLP-1 modulates satiety and reduces gastric emptying and is thus associated with weight loss. These multiple effects have generated a great deal of interest in the discovery of long-lasting agonists of the GLP-1 receptor (GLP-1R) in order to treat type 2 diabetes. The receptor for GLP-1 (GLP-1R) was first cloned from a cDNA library derived from rat pancreatic islets, and the following year, the human receptor was cloned. The cloning revealed a receptor sequence of 463 residues that resembled the receptors for secretin, parathyroid hormone and calcitonin. These receptors formed a new branch of the GPCR superfamily, named 'Family B' (or 'Class B', or 'secretin receptorlike'), which to date includes 15 members. These receptors possess a unique extracellular N-terminal domain (NTD) of 100-150 residues, which is connected to the integral membrane core domain (or J domain) that is typical of all GPCRs. Family B GPCRs bind their peptide ligands via a common mechanism known as the 'two-domain model' in which the NTD first binds to the C-terminal helical region of the ligand, thereby enabling a second interaction between the N-terminal region of the ligand and the core domain of the receptor. The latter interaction is essential for enabling agonist-induced receptor activation. [2]

Our aims were the chemical synthesis, oxidation and characterization of GLP-1 peptide receptor fragments and the investigation of the peptide-ligand (GLP-1, liraglutide, exendin) interaction using NMR spectroscopy.

Due to the difficulty and the length of the sequence we have decided to synthesize the 108 amino acid containing GLP-1 peptide receptor by native chemical ligation procedure. The designed fragments compatible with native chemical ligation was synthesized using solid phase peptide synthesis applying Fmoc/tBu strategy and the synthesis was carried out using a $\mathrm{CEM}^{\circledR}$ microwave assisted fully automated peptide synthesizer. 


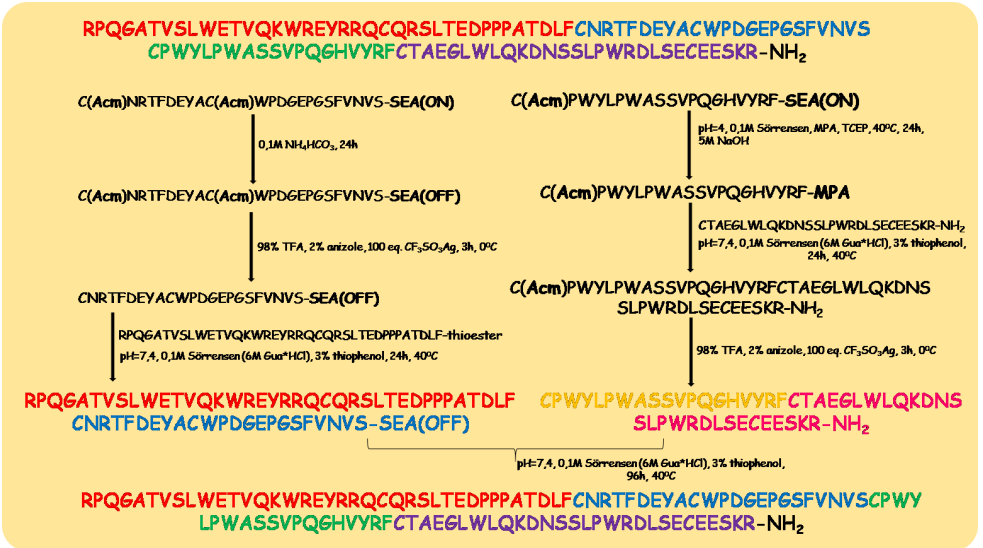

Scheme 1: The synthesis of GLP-1 receptor by native chemical ligation (NCL)

The synthesis of RPQGATVSLWETVQKWREYRRQCQRSL TEDPPPATDLF-thioester (fragment 1)

The synthesis of peptide thioester (fragment 1) was carried out using manual solid phase peptide synthesis applying Boc chemistry. First a Fmoc-Cys(Trt)-OH was attached to the MBHA resin using DCC/HOBT coupling. After that the Fmoc group was removed by using 20\% piperidine/DMF and the resulting free amino group was acetylated using 30\% acetic anhydride/dichloromethane. The trityl group was removed by the treatment of TFA. The first amino acid was attached to the free sulfhydryl group of cysteine by applying DCC/HOBT double coupling in the presence of DMAP.

The synthesis of CNRTFDEYACWPDGEPGSFVNVS-SEA(OFF) (fragment 2)

The peptide fragment 2 was synthesized using a CEM fully automated microvawe assisted peptide synthesizer applying Fmoc/tBu chemistry, using SEA resin, and Acm side chain protection for cysteins. The crude SEA-(ON) peptide was oxidized using $0,1 \mathrm{M} \mathrm{NH} 4 \mathrm{HCO} 3$ to obtain the crude SEA-(OFF) peptide. The Acm side chain protection was removed by using $\mathrm{Ag}(\mathrm{OTf})$ (50eq.) in TFA $(10 \mathrm{mg} / \mathrm{ml})$ in the presence of anisole at $4^{\circ} \mathrm{C}$ for $4 \mathrm{~h}$.

The chemical ligation of peptide thioester (fragment1) and SEA-(OFF) peptide (fragment2) was carried out in the presence of thiophenol (3\%) in 0,1M Sörrensen buffer, $\mathrm{pH}=7,4\left(6 \mathrm{M} \mathrm{Gua}{ }^{\star} \mathrm{HCl}\right)$, at $40^{\circ} \mathrm{C}$ for $24 \mathrm{~h}$.
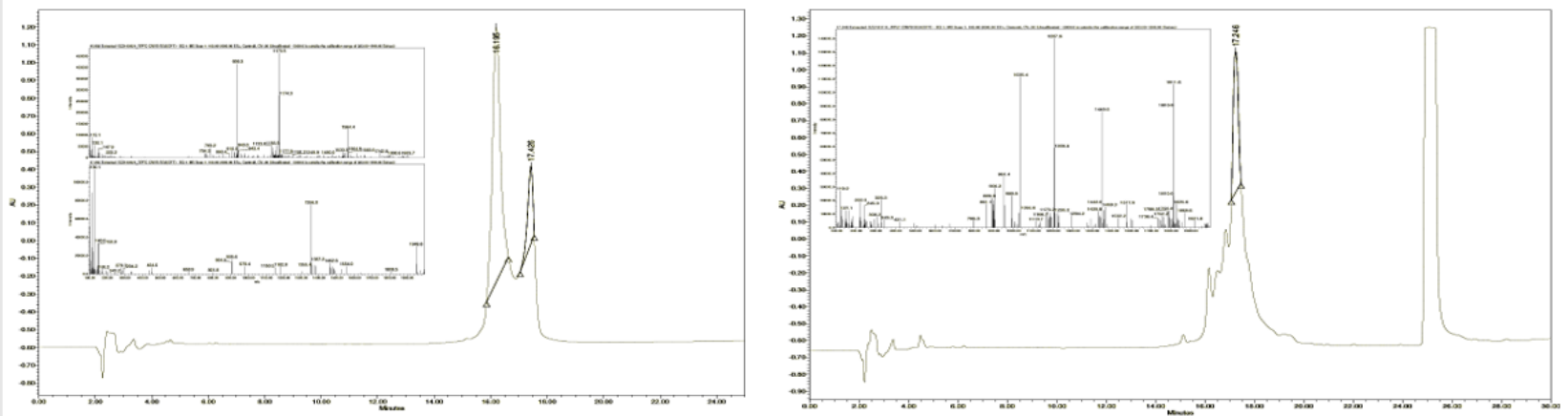

Scheme 2: The chemical ligation of peptide thioester (fragment 1) and SEA-(OFF) peptide (fragment 2), Omin (left side); The mass spectra and LC-chromatogram of ' $N$ "' terminal GLP-1 receptor fragment obtained by chemical ligation (24h) (right side)

The synthesis of C(Acm)PWYLPWASSVPQGHVYRF-MP A (fragment 3)

The peptide fragment 3 was synthesized using a CEM fully automated microvawe assisted peptide synthesizer applying Fmoc/tBu chemistry, using SEA resin. The side chain of the " $N$ " terminal cystein was protected with Acm protecting group. The crude Acm protected SEA-(ON) peptide was coverted into Acm protected peptide-MPA thioester by using MPA (mercaptoproionic acid), in the presence of TCEP (1000eq.) in 0,1M Sörrensen buffer $\left(6 \mathrm{M} \mathrm{Gua}{ }^{\star} \mathrm{HCl}\right)$ at $40^{\circ} \mathrm{C}, \mathrm{pH} 4$ for $24 \mathrm{~h}$. 
The peptide amide (fragment 4) was synthesized using a CEM fully automated microvawe assisted peptide synthesizer applying Fmoc/tBu chemistry. The chemical ligation of the Acm protected peptide-MPA thioester (fragment3) and the peptide amide (fragment 4) was carried out in the presence of thiophenol (3\%) in $0,1 \mathrm{M}$ Sörrensen buffer $\mathrm{pH}=7,4\left(6 \mathrm{M} \mathrm{Gua}{ }^{*} \mathrm{HCl}\right)$, at $40^{\circ} \mathrm{C}$ for $24 \mathrm{~h}$.
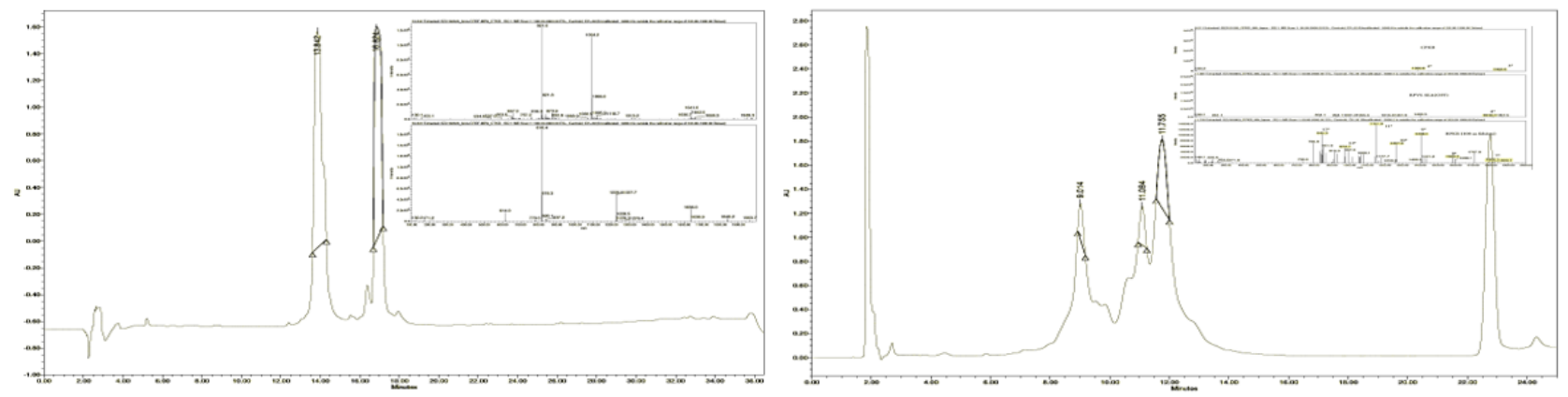

Scheme 3: The chemical ligation of Acm protected peptide-MPA thioester (fragment 3) and peptide amide (fragment 4), Omin (left side); The mass spectra and LC-chromatogram of Acm protected ' $C$ '" terminal GLP-1 receptor fragment obtained by chemical ligation (24h) (right side)

The Acm protection of the "C" terminal peptide was removed by using $\mathrm{Ag}(\mathrm{OTf})$ (50eq.) in TFA (10mg/ml) in the presence of anisole at $4^{\circ} \mathrm{C}$ for $4 \mathrm{~h}$. The chemical ligation of " $\mathrm{N}$ " terminal SEA-(OFF) peptide and the Acm deprotected " $\mathrm{C}$ " terminal peptide amide was carried out in the presence of thiophenol (3\%) in 0,1M Sörrensen buffer, $\mathrm{pH}=7,4,\left(6 \mathrm{M} \mathrm{Gua}{ }^{\star} \mathrm{HCl}\right), 0,2 \mathrm{M} \mathrm{TCEP}{ }^{\star} \mathrm{HCl}$ at $40^{\circ} \mathrm{C}$ for $96 \mathrm{~h}$.
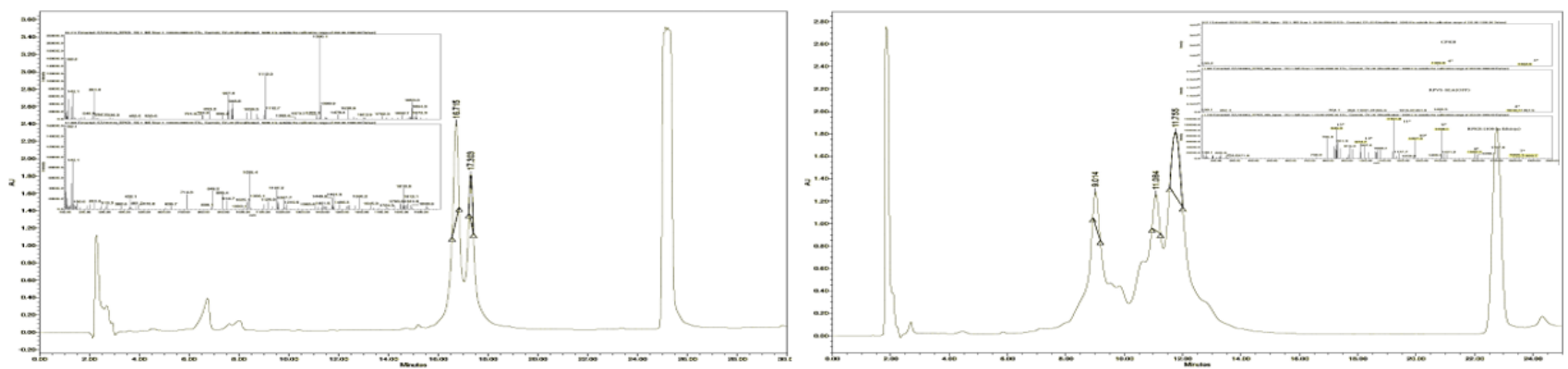

Scheme 4: The chemical ligation of of " $N$ " terminal SEA-(OFF) peptide and the Acm deprotected " $C$ " terminal peptide amide, Omin (left side); The mass spectra and LC-chromatogram of GLP-1 receptor obtained by chemical ligation (96h) (right side)

To obtain the desired disulfide bridges the purified 108 amino acid containing linear GLP-1R peptide was oxidized using different oxidation conditions. (see table 1.) Because of the presence of 6 cystein residues $\left(\mathrm{C}_{23(\mathrm{~A})}\right.$, $\left.\mathrm{C}_{39(\mathrm{~B})}, \mathrm{C}_{48(\mathrm{C})}, \mathrm{C}_{62(\mathrm{D})}, \mathrm{C}_{81(\mathrm{E})}, \mathrm{C}_{103(\mathrm{~F})}\right)$ the formation of three disulfide bonds was expected, but unfortunately none of the applied oxidation conditions were successful. 


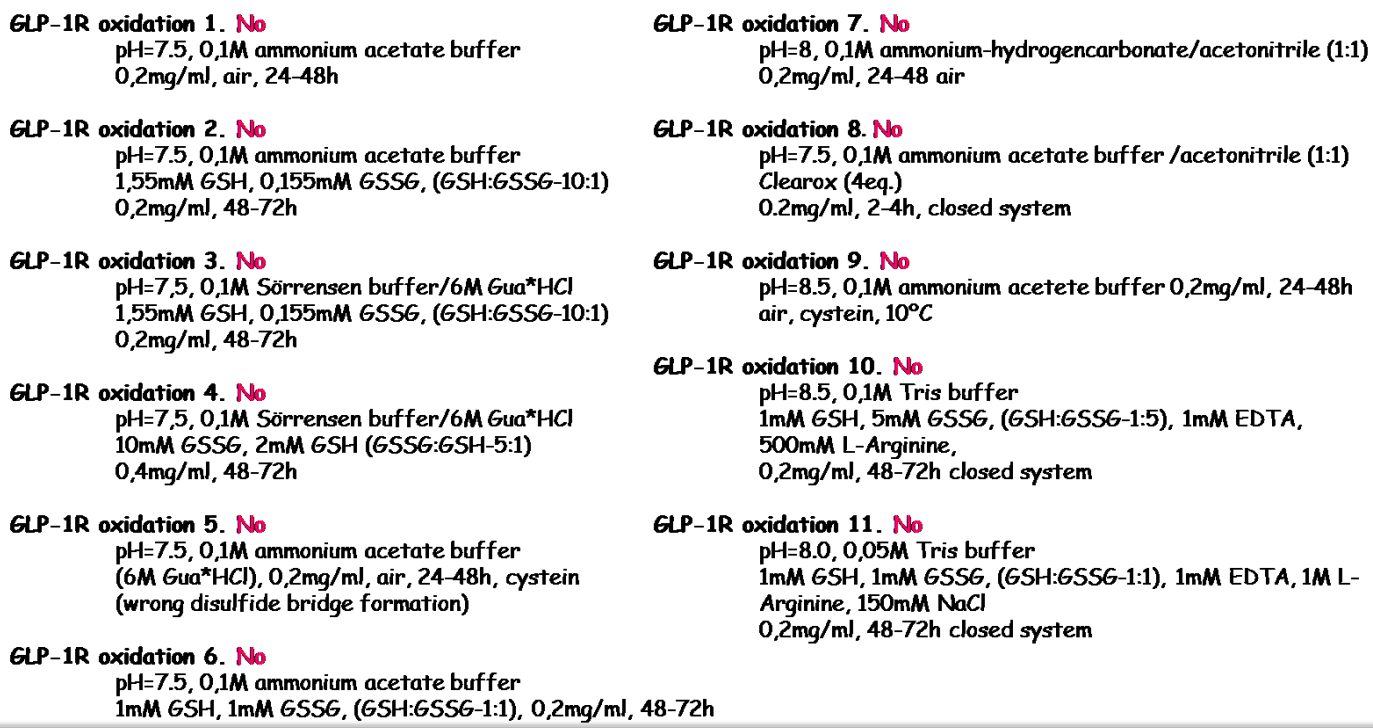

Figure 1

The synthesis of a GLP-1R by gene expression using MBP

GSRPQGATVSLWETVQKWREYRRQC $_{(A)}$ QRSLTEDPPPATDLFC $_{(B)}$ NRTFDEYAC $_{(C)}$ WPDGEPGSFVNVSC $_{(D)}$ PWYLPWASSVPQGHVYRFC (E) TAEGLWLQKDNSSLPWRDLSEC (F) EESKRG-NH ${ }_{2}$
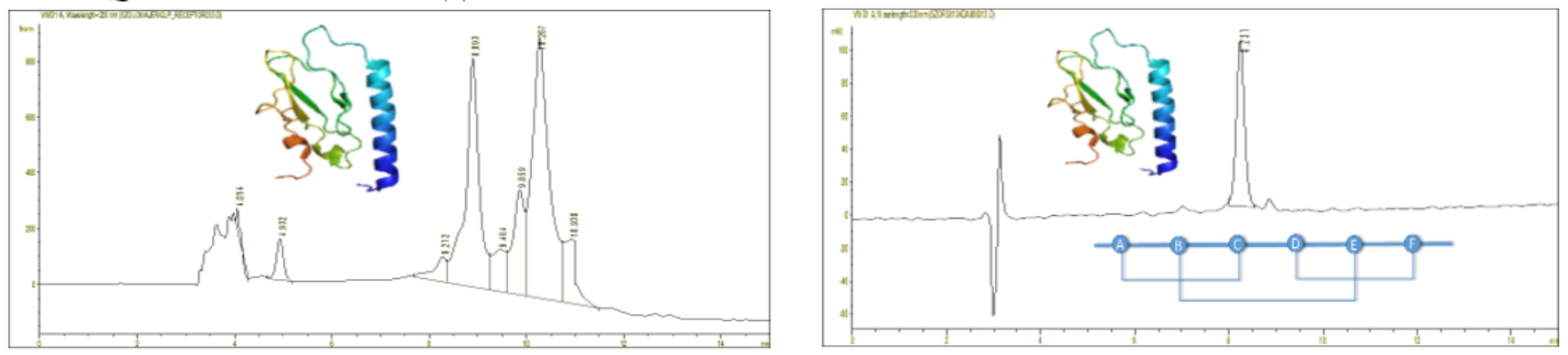

Scheme 5: The LC-chromatogram of oxidized GLP-1R containing protein mixture (right side); The $L C$-chromatogram of purified, oxidized GLP-1R having the desired disulfide bridges

The oxidation of linear GLP-1R obtained by native chemical ligation, and the investigation of the peptide ligand (GLP, exendine, liraglutide) interaction using NMR spectroscopic method are still in progress.

\section{References}

1. Insuela, D.B.R. and V.F. Carvalho, Glucagon and glucagon-like peptide-1 as novel anti-inflammatory and immunomodulatory compounds. European Journal of Pharmacology, 2017. 812: p. 64-72.

2. Donnelly, D., The structure and function of the glucagon-like peptide-1 receptor and its ligands. British Journal of Pharmacology, 2012. 166(1): p. 27-41. 